\title{
DITIOENG MEMEH HOEDJAN: \\ PEMIKIRAN PANGERAN ARIA SURIA ATMADJA DALAM MEMAJUKAN PEMUDA PRIBUMI DI SUMEDANG (1800-1921)
}

\author{
DITIOENG MEMEH HOEDJAN: \\ THE TOUGHT OF PRIN CE SURIA ATMADJA'S \\ IN DEVELOPING INDIGENOUS YOUTH IN SUMEDANG
}

\author{
Lasmiyati \\ Balai Pelestarian Nilai Budaya Bandung, \\ Jln. Cinambo 136 Ujungberung Bandung \\ e-mail: lasmiyatinizam@gmail.com
}

\begin{abstract}
Abstrak
Pangeran Aria Suria Atmadja telah memajukan Sumedang di berbagai sektor seperti pertanian, perikanan, kehutanan, politik, kebudayaan, dan sektor lainnya. Atas jasa-jasanya dalam memajukan Sumedang, pada 25 April 1922 didirikan monumen berbentuk Lingga yang diresmikan oleh Gubernur Jenderal D. Fock. Pada masa pemerintah kolonial Belanda di bawah Gubernur Jenderal Paul van Limburg Stirum menguasai wilayah Sumedang, Pangeran Aria Suria Atmadja mengusulkan agar para pemuda pribumi dilatih menggunakan senjata. Penelitian ini dilakukan untuk mengetahui sosok Pangeran Aria Suria Atmadja, bagaimana dan dalam bidang apa beliau berkiprah untuk memajukan Sumedang dan bagaimana reaksi pemerintah kolonial terhadap kiprahnya. Tulisan berjudul Ditioeng Memeh Hudjan merupakan karya luhung Pangeran Aria Suria Atmadja yang berisikan keinginan, cita-cita, dan harapan untuk memajukan pemuda pribumi di Sumedang. Metode yang digunakan adalah metode sejarah yang meliputi heuristik, kritik, interpretasi, dan historiografi. Dari hasil penelitian yang dilakukan diperoleh informasi bahwa usulan Pangeran Aria Suria Atmadja agar pemerintah kolonial melatih para pemuda untuk menggunakan senjata ditolak. Pemerintah kolonial bereaksi dengan membuat tiga benteng pertahanan di Sumedang.
\end{abstract}

Kata kunci: Sumedang, Pangeran Aria Suria Atmadja, pelatihan militer.

\begin{abstract}
The prince Aria Suria Atmadja drummed up Sumedang in various sectors as well as agriculture, fishery, forestry, politics, culture, and other sectors. Because of his merit, on April 25 th the Governor General D. Fock build a monumen, and the monumen shaped is Lingga (). In the era of Dutch colonialism, General Paul van Limburg Stirum hold the governor of Sumedang.In that time, Prince Aria Suria Atmadja was raising a new issue that the young people have to train in using a weapon (gun). What to do with this research is to know the figure of Prince Aria Suria Atmadja, especially to know the ways of Prince Aria in developing Sumedangand to find out the reaction of dutch collonial which is caused by the movement of the prince. The writtten entitled Ditioeng Memeh Hudjanis one of the greatest masterpiece of Prince Aria Suria Atmadja, which is containing his will, hope and expectation in drumming up young people in Sumedang. The method that writer used are related with Heuristic, criticism, interpretation, and historygraphy. The result of the research show us that the suggestions of Prince Aria Suria Atmadja related to the use
\end{abstract}


weapon (gun) was rejected by the dutch collonial. The dutch collonial also build three defence fortress in Sumedang as the response to the movement.

Keywords: Sumedang, Pangeran Aria Suria Atmadja, military training.

\section{A. PENDAHULUAN}

Sumedang merupakan salah satu kabupaten di Jawa Barat. Secara etimologi kata Sumedang berasal dari dua suku kata, su yang artinya bagus dan medang yang artinya luas. Sewaktu Sumedang menjadi kerajaan, nama sumedang diikuti kata larang yaitu Sumedang Larang artinya tanah luas, bagus, jarang bandingannya (Jubaedah, 2005: 13). Dalam legenda yang berkembang di masyarakat Sumedang, kata Sumedang pertama kali diucapkan oleh Prabu Tajimalela, ketika akan menyerahkan tahta kekuasaannya kepada puteranya Prabu Gajahagung. Bertepatan dengan penyerahan tahta tersebut, di pelataran Tembong Agung (wilayah Tajimalela berkuasa) terpancar sinar cahaya terang yang melengkung bagaikan selendang. Dari cahaya terang tersebut, Prabu Tajimalela berucap insun medal insun madangan. Insun medal artinya aku dilahirkan. insun madangan artinya memberi penerangan. Dari kata insun madangan tersebut kemudian berubah pengucapan menjadi Sumedang (Lubis, 2000: 71).

Pada tahun 1614 , VOC mengirim utusan ke Mataram yang waktu itu diperintah oleh Sultan Agung. Kepada utusan VOC Sultan Agung menyampaikan klaim bahwa seluruh wilayah Jawa Barat kecuali Banten dan Cirebon berada dibawah kekuasaannya. Hal itu membuat Aria Suriadiwangsa ketakutan. Raden Suriadiwangsa khawatir Mataram akan menyerangnya. Atas kemauannya sendiri pada 1620 Aria Suriadiwangsa datang ke Mataram menemui Sultan Agung untuk menyatakan pengakuannya bahwa Sumedang menjadi bawahan Mataram. Karena ketulusan hati Pangeran Suriadiwangsa yang mengakui hegemoni kesultanan Mataram inilah, wilayah yang dikuasai Pangeran Aria Suriadiwangsa dinamai Prayangan (yang artinya tulus ikhlas), dari kata ini diperkirakan lahir kata Priangan ${ }^{1}$. Sejak saat itu pula Sumedang menjadi sebuah kabupaten di bawah kekuasaan Mataram. Aria Suriadiwangsa kemudian menduduki jabatan baru sebagai wedana bupati ${ }^{2}$. Ia juga diberi baju dan payung kebesaran selayaknya seorang raja dan mendapat gelar Pangeran Dipati Rangga Gempol I Kusumadinata. Meskipun demikian derajat kedudukannya sebagai seorang raja telah turun dibandingkan jabatan raja yang disandang ayahandanya Prabu Geusan Ulun, sebab jabatannya sebagai wedana bupati secara tidak langsung berkiblat ke Mataram.

Dengan meninggalnya Sultan Agung, kejayaan Mataram menjadi lemah, selain konflik internal juga akibat serangan dari luar yakni VOC (Kumpeni). Dengan lemahnya kekuatan Mataram, satu per satu daerah kekuasaan Mataram yang pernah ditaklukkannya menjadi daerah kekuasaan VOC. Pada masa kekuasaan Tanumadja, kumpeni Belanda ikut campur dalam urusan kabupatian, di antaranya pengangkatan Tanumadja sebagai bupati. ${ }^{3}$

\footnotetext{
${ }^{1}$ Priangan berasal dari kata Prayangan yang artinya penyerahan diri dengan hati suci (Lubis, 2000: 125)

2 Pada zaman Mataram dikenal dua macam sebutan bupati. Pertama wedana bupati yaitu bupati yang mengepalai sejumlah bupati (kepala daerah) dalam wilayah teritorial tertentu. Kedua adalah bupati yaitu sebutan untuk kepala-kepala daerah yang memimpin kabupaten di wilayah mancanegara (Hardjasaputra, 2004: 12).

3 Bupati berasal dari kata bhu yang berarti bumi atau tanah dan pati yang berarti tuan atau pemilik yang artinya raja.
} 
Pengangkatan Tanumadja sebagai bupati Sumedang pada 1706, tidak langsung definitif, apabila sikap Tanumadja dinilai loyal kepada pemerintah Kompeni ia akan dikukuhkan sebagai bupati definitif (Herlina Lubis, 2008: 145).

Pemerintah Kolonial selain telah ikut campur dalam pengangkatan bupati, mereka juga mendirikan benteng pertahanan ${ }^{4}$, pemukiman, tangsi militer, bahkan rumah sakit militer.

Penelitian ini dibatasi pada kurun waktu 1800-1921, dengan alasan pada 1800, Daendels sebagai gubernur jenderal Belanda membangun sarana kota di Batavia. Dari Batavia Daendels berkeinginan untuk memindahkan ibukota Hindia Belanda ke Kota Bandung, dengan alasan secara geografis Bandung berdekatan dengan Batavia dan keberadaan pegunungan, perbukitan yang terjal, dan benteng alam yang kokoh dapat melidungi dari serbuan musuh. Pemusatan pasukan pertahanan difokuskan di kedua pintu yaitu di sebelah barat dibangun pusat militer di Cimahi dan sebelah timur di Sumedang (http://geohistori.blogspot. com). Yang menjadi pertanyaan siapakah Pangeran Aria Suria Atmadja, bagaimana dan dalam bidang apa beliau berkiprah untuk memajukan Sumedang dan bagaimana sikap pemerintahan kolonial Belanda terhadapnya. Penelitian ini bertujuan menjawab permasalahan tersebut.

Salah satu tulisan yang mengupas mengenai Pangeran Aria Suria Atmaja adalah tulisan Dr. Mumuh Muhsin mengenai pengusulan Pangeran Aria Suria Atmaja menjadi pahlawan nasional (Muhsin dalam pustaka. unpad.ac.id).

\footnotetext{
${ }^{4}$ Benteng adalah bangunan tempat berlindung atau bertahan dari serangan musuh. Hanya yang sempat berlindung di dalamnya yang selamat. Kata lain dari benteng adalah tempat untuk menahan serangan (Sugono, 2005: 173).
}

\section{B. METODE PENELITIAN}

Metode yang digunakan adalah metode sejarah yang meliputi tahap heuristik, yaitu tahap mencari dan menemukan sumber, baik sumber primer maupun sekunder. Langkah berikutnya adalah melakukan kritik sumber untuk mengetahui apakah sumber-sumber tersebut valid dan dapat dipercaya. Setelah sumber-sumber dikritik baik ekstern maupun intern, langkah berikutnya adalah interpretasi, baru kemudian dilakukan penulisan atau historiografi, yaitu merangkaikan fakta hingga menjadi tulisan sejarah.

Dalam artikel ini penulis mempergunakan teori dan konsep kepemimpinan. Kepemimpinan ditafsirkan sebagai hubungan yang erat antara seseorang dan sekelompok manusia karena adanya kepentingan bersama. Hubungan itu ditandai oleh tingkah laku yang tertuju dan terbimbing dari manusia yang seorang itu. Manusia dan orang itu biasanya disebut pemimpin, sedangkan kelompok manusia yang mengikutinya disebut yang dipimpin (Tamburaka, 1999: 92). Rustam E. Tamburaka juga mengatakan bahwa dasar potensi sumber daya yang dimiliki seseorang merupakan modal talenta untuk menjadikannya sebagai seorang pemimpin.

Selain itu digunakan teori pembangunan teknokrasi yaitu suatu teori yang dikembangkan oleh sekelompok ahli pembangunan pedesaan/perkotaan yang memandang pembangunan hanya mungkin terlaksana jika dimulai dengan suatu tindakan, suatu intervensi dari pihak luar. Tindakan itu memperkenalkan latihan kalau perlu memaksakan penerapan/aplikasi suatu teknologi produksi yang modern dan canggih. Konsep ini dalam implementasinya di bidang pembangunan fisik cukup mengagungkan dengan keberhasilannya membangun industri-industri, gedunggedung yang monumental, namun di sisi lain timbul kehampaan jiwa masyarakat pendukungnya. Timbul kerawanan dan 
ketimpangan karena tidak diperhatikan pembangunan segi mental/spiritual. Max Weber menyebutnya sebagai "kekecewaan" (Tamburaka, 1999: 118119).

Selain itu penulis juga mempergunakan konsep sensibility (sensibilitas) yaitu kehidupan emosional manusia. Konsep sensibilitas yang pernah ditulis oleh Lucian Febvre. Ia mengharapkan adanya jenis sejarah baru tentang cinta, kesedihan, ampunan, berkah, kematian, belas kasihan, kekejaman, ketakutan, kebencian, dan sebagainya. Secara khusus ia menunjuk pentingnya sastra. Karya sastra bukan saja mampu memberi bayangan tentang sensibilitas, tetapi juga tentang cara-cara mencipta kemudian menyebarkan bentuk-bentuk sensibilitas kepada massa secara tepat (Kuntowijoyo, 2003: 238).

\section{HASIL DA N BAHASA N}

\section{Pemindahan Pusat Komando Hindia Belanda ke Pedalaman}

Pada 1807, Daendels diangkat sebagai gubernur jenderal di Nusantara. Ia diberi tugas untuk memperbaiki keadaan dan kesehatan kota. Apabila Daendels tidak berhasil, ia diwajibkan mengajukan usul untuk kemungkinan pemindahan ibu kota koloni milik Belanda di Asia ke tempat lain di Pulau Jawa yang lebih cocok, karena Batavia yang pernah mendapat julukan sebagai 'Ratu dari Timur' telah menjadi kota yang sepi. Daendels memindahkan pusat pemerintahannya ke Weltevreden ${ }^{5}$. Andil Daendels dalam membina dan mengembangkan Kota Batavia cukup besar. Ia ditugasi untuk mengorganisasi

\footnotetext{
${ }^{5}$ Daerah yang dinamakan weltevreden adalah Batavia, waktu itu mempunyai batas wilayah di sebelah utara postweg dan Schoolweg (sekarang Jalan Pos dan Jalan Dr.Sutomo). di sebelah timur dengan Groote Zuiderwegg (sekarang Jalan Gunung Sahari, Pasar Senen, dan Kramat Jati). Di sebelah selatan dari jembatan Kramat sampai jembatan Perapatan di sebelah barat Sungai Ciliwung.
}

pertahanan menghadapi Inggris dan mengadakan perubahan-perubahan pemerintah kolonial, sekaligus berkewajiban untuk memperbaiki kesehatan warga Kota Batavia. Daendels kemudian membuat rencana besar untuk mengubah Weltevreden menjadi ibu kota baru yang sehat. Pada 1810, Daendels memerintahkan untuk membongkar tembok kota dan menghancurkan benteng Batavia. Sebagian batu-batunya dipergunakan untuk membangun Weltevreden. Ia memerintahkan Letkol Schuetz untuk merencanakan sebuah istana baru, tempat kediaman resmi gubernur jenderal. Istana dibangun dekat Waterlooplein (sekarang Lapangan Banteng). Sebagian dari bahan bangunannya diambil dari Kasteel Batavia (Yayasan Untuk Indonesia, 2005: xxx). Pada 1811, Armada Pasukan Inggris di bawah pimpinan Lord Minto berhasil menyerbu pantai Cilincing, Cirebon, dan Semarang. Dengan demikian, pertahanan Belanda di daerah pantai utara Pulau Jawa menjadi lemah. Dengan adanya peristiwa tersebut menjadikan para petinggi militer Hindia Belanda trauma untuk bertahan di pantai. Mereka menginginkan untuk memindahkan pusat komandonya ke daerah Priangan (Bandung-Cimahi). Namun rencana tersebut sempat terhenti. Keinginan akan pemindahan ibu kota Hindia Belanda di Nusantara yang bertempat di Batavia kembali mencuat. H.F. Tilema warga negara Belanda kelahiran Groningen mengusulkan kalau Batavia sudah tidak cocok sebagai ibu kota disebabkan berada di pantai yang cuacanya panas. Upaya pemindahan pun mulai dirintis pada 1896 , Cimahi dijadikan Garnizun militer dan 1898 pemindahan pabrik mesiu dari Ngawi (Madiun) dan pabrik senjata "Artillerie Constructie Winkel" dari Surabaya dipindahkan ke Bandung (Kunto, 1986: 922). Dengan dipindahkan pusat komando militer ke Bandung-Cimahi, Sumedang akan dijadikan sebagai daerah 
penyangga ibu kota (Wawancara dengan Ahmad Wiriatmadja, 11 Januari 2014).

Guna mendukung Bandung sebagai ibu kota pemerintahan yang baru, pemerintah kolonial membangun rel kereta api sebagai sarana transportasi darat. Pembangunan rel kereta api lintas Banten dari Jakarta ke Anyer Kidul selesai dibangun pada 1900. Untuk menghubungkan daerah di sebelah timur Jakarta, lintas Jakarta-Bekasi, sampai Karawang, kemudian lintas JakartaKarawang dilanjutkan ke Padalarang melewati Cikampek dan Purwakarta. Pada Juni 1912 terlaksanalah hubungan jalan rel dari Jakarta sampai Surabaya, bahkan dari Anyer di ujung barat Pulau Jawa hingga Banyuwangi di ujung timur Pulau Jawa, melalui jalur-jalur JakartaBogor- Bandung-Yogyakarta-Madiun. Jakarta-Cikampek-Bandung-Yogyakarta Madiun. Jakarta-Cirebon-SemarangBojonegoro (Subarkah, 1992: 14). Pemerintah Kolonial juga membangun Pelabuhan Udara Andir (sekarang Lapangan Udara Husein Sastranegara). Pada 1914, lapangan udara tersebut diresmikan sebagai pusat pangkalan militer di Hindia Belanda (Kunto, 1986: 926). Dengan demikian, keberadaan Lapangan Udara Andir semakin penting karena selain sebagai lapangan terbang sipil juga berfungsi sebagai pangkalan militer. Lapangan Terbang Andir dapat diposisikan sebagai salah satu lapangan terbang terpenting di Hindia Belanda. Melalui Lapangan Terbang Andir, evakuasi pejabat militer dan sipil Belanda ke Australia dilakukan apabila posisi Belanda semakin terdesak oleh gangguan dari luar.

Di Bandung juga dibangun stasiun kecil yaitu Cimahi dan Rancaekek. Fasilitas kereta api di stasiun Cimahi digunakan untuk mengangkut bahanbahan pokok, sayur-mayur, kopi, tembakau, dan sebagai sarana angkutan personil militer (Lubis, 2004: 21). Guna menunjang Sumedang yang akan dijadikan sebagai kota penyangga ibu kota yang direncanakan berada di Bandung, pemerintah kolonial membangun jalur rel kereta api dari Rancaekek ke Tanjungsari, yang kemudian akan dilanjutkan pembangun rel kereta api dari Tanjungsari ke Sumedang. Namun pembangunan rel kereta api dari Tanjungsari ke Sumedang tersebut baru tahap rencana dan belum seluruhnya terlaksana (wawancara dengan Ahmad Wiriatmadja, 11 Januari 2014). Pada 1918, SS (Staat Spoorwagen) membangun jalan Kereta Api jurusan Rancaekek-Jatinangor-Tanjungsari yang digunakan untuk mengangkut komoditas utama seperti teh, kopi, tembakau, dan lain-lain (Solihat, 2005: 21). Untuk memperkuat pertahanan, Cimahi juga dihubungkan jalur Jalan Kereta Api menuju pusat pertahanan Belanda di Samudera Hindia, yaitu Cilacap (Hermawan, diakses dari httt:geohistori. blogspot.com) .

\section{Pangeran A ria Suria A tmaja}

Pangeran Suria Atmaja adalah putra Pangeran Suria Kusumah Adinata (Pangeran Sugih). Ia dilahirkan pada 11 Januari 1851. Sebelum menjabat sebagai bupati, ia bernama Pangeran Sadeli dan pernah menjadi patih afdeling Sukapura Kolot di Mangunreja. Ia termasuk anak yang cerdas, jujur, dan selalu mendekatkan dirinya kepada Allah SWT. Pangeran Suria Atmadja dilantik sebagai bupati Sumedang pada 31 Januari 1883 pada usia 32 tahun (Suryaman et al., 1996: 42). Dalam pelantikan tersebut ia mendapat gelar Aria. Pangeran Aria Suria Atmaja merupakan bupati terakhir, sehingga mendapat sebutan Pangeran Panungtung ${ }^{6}$ (www.babadsunda.blogspt.co $m)$.

\footnotetext{
${ }^{6}$ Dinamakan Pangeran Panungtung disebabkan Pangeran Aria Suria Atmadja tidak mempunyai anak laki-laki yang berhak menggantikan kedudukannya sebagai bupati. Seusai Pangeran Aria Suria Atmadja menjabat sebagai bupati, yang menggantikan kedudukannya adalah adiknya. Bahkan Pangeran Aria Suria Atmadja pernah berkata kepada adiknya bahwa nantinya yang akan
} 
Selama menjabat sebagai bupati Sumedang, ia memajukan berbagai bidang, di antaranya meningkatkan hasil peternakan, mendatangkan sapi dari Madura dan Benggala, kuda dari Sumba atau Sumbawa. Di bidang kehutanan ia menganjurkan penanaman pohon agar gunung yang gundul tidak longsor, dan dibuat hutan larangan/hutan tertutup agar hutan tersebut tidak terganggu kelestariannya. Untuk memperlancar sarana komunikasi, ia membangun kantor telepon. Untuk menyejahterakan rakyat kecil, ia membangun "Bank Prijaji" pada 1901, dan pada 1910 nama Bank Priyayi berubah menjadi "Soemedangsche Afdeeling Bank". Di bidang kebudayaan, Pangeran Aria Suria Atmadja memajukan bidang kesenian yaitu Tari Tayub dan Degung. Ia membuat buku dan menciptakan lagu "Sonteng". Bidang lainnya, ia membangun rumah untuk para kepala onderdistrik. Selama menjabat sebagai bupati, Pangeran Aria Suria Atmadja menunjukkan seorang pemimpin yang arif serta mementingkan kesejahteraan rakyatnya. Upaya yang dilakukan dalam meningkatkan taraf hidup rakyatnya, ia memperbaiki segala sektor kehidupan. Ia menginginkan agar rakyatnya menjadi petani yang maju. Di bidang pertanian ia membangun irigasi untuk mengairi sawah, membangun lumbung desa, dan pembuatan sistem tangga (terasering) pada bukit-bukit. Pada 1913, Ia juga mendirikan sekolah tani yang merupakan cikal bakal Akademi Pertanian Tanjungsari (APT), APT ini kemudian berkembang menjadi Universitas Winayamukti/Unwim (Suryaman et al., 1996: 43). Pada 1915 dibangun Hollandsch Inlandsche School. Untuk menjaga keamanan, dibangun pos-pos keamanan mulai dari tingkat desa, kecamatan, hingga tingkat kawedanaan yang difungsikan untuk penjaga ronda

menggantikan bupati-bupati berikutnya adalah bukan dari leluhur Sumedang. malam. Selain itu, di setiap pos tertentu juga disediakan peralatan penanggulangan kebakaran dengan cara tiap-tiap pos diwajibkan untuk menyediakan air dalam bambu dan menyediakan pasir-pasir serta peralatan kebakaran lainnya. Semua kegiatan tersebut harus dilaporkan setiap rapat mingguan langsung diawasi oleh bupati (Suryadi, 1972: 11). Programprogram yang dilakukan Pangeran Aria Suria Atmadja tersebut tidak mendapat reaksi negatif dari pemerintah Belanda, justru pemerintah Belanda melalui gubernur jenderal menyetujui langkahlangkah yang diambil Pangeran Aria Suria Atmadja tersebut.

Pangeran Aria Suria Atmadja tidak hanya memerhatikan masalah kesejahteraan rakyatnya. Ia juga memajukan para pemuda untuk dapat berlatih militer. Ia berkenginan agar rakyatnya dapat merdeka dan para pemuda pribumi dapat memegang senjata. Pangeran Aria Suria Atmaja mengajukan hal tersebut kepada pemerintah kolonial agar para pemuda diseleksi dan dilatih mempergunakan senjata dengan alasan untuk mengikuti bela negara. Apabila sewaktu-waktu terjadi serangan dari luar, rakyat bisa turut membantu mempertahankan daerahnya. Ide tersebut dituangkan ke dalam tulisannya berjudul Indie Weerbaar (ketahanan Hindia) (Lubis, 2008: 172). Bagi Pangeran Aria Suria Atmadja, permintaan agar pemerintah kolonial melatih para pemuda pribumi untuk dapat mempergunakan senjata, sudah dipikirkan jauh ke depan, bahwa nantinya para pemuda pilihan tersebut dapat merebut kemerdekaan. Cita-cita Pangeran Aria Suria Atmadja ternyata terbaca juga oleh pemerintah kolonial. Usul tersebut ditolak pemerintah kolonial. Pemerintah kolonial beranggapan bahwa usulan Pangeran Aria Suria Atmaja bertujuan untuk melakukan perlawanan sehingga akan mengancam kedudukannya. Bagi Belanda permintaan Pangeran Aria Suria Atmadja tersebut dianggap sangat berlebihan. Pemerintah kolonial 
mengkhawatirkan andaikata usulan Pangeran Aria Suria Atmadja tersebut dilakukan akan menjadikan senjata makan tuan, yaitu rakyat Sumedang akan memberontak. Untuk mengantisipasi pengikut Aria Suria Atmadja dalam melakukan perlawanan, Belanda membangun benteng pertahanan.

\section{Benteng Pertahanan Belanda}

Sebelum membangun benteng pertahanan, terlebih dahulu pemerintah kolonial membangun Tangsi Belanda (sekarang digunakan untuk kantor Kodim 0610 Sumedang). Kemudian dibuat jalan militer menuju benteng-benteng pertahanan, seperti sebelah utara menuju Benteng Palasari dan sebelah selatan menuju Gunung Gadung, Gunung Kunci, Dam Ragadiem, dan menuju ke Gunung Datar (arah ke Subang) (wawancara dengan Ahmad Wiriatmadja, 11 Januari 2014). Pembangunan jalan tersebut untuk mempermudah jalur transportasi dari tangsi militer menuju benteng pertahanan.

Benteng pertahanan yang dibangun adalah:

\section{a. G unung Kunci}

Gunung Kunci terletak di Dusun Panjunan Kelurahan Kotakulon Kecamatan Sumedang Selatan Kabupaten Sumedang. Gunung Kunci dijadikan benteng pertahanan, dibangun di antara kawasan Hutan Raya Gunung Kunci dan Gunung Palasari. Gunung Kunci dibangun 1917 pada masa Gubernur Jenderal Van Limburg Stirum yang memerintah dari tahun 1916-1921. Pembangunan benteng pertahanan tersebut bersamaan dengan dibangunnya benteng pertahanan militer Belanda lainnya di Gunung Palasari, Gunung Gadung, dan Pasirbilik (wawancara dengan Enjang, 26 Desember 2013).

Sumedang secara geografis dikelilingi oleh gunung, sehingga memungkinkan untuk dijadikan tempat pertahanan. Dengan alasan inilah rupanya Belanda membangun benteng pertahanan di kota ini. Benteng Pertahanan Belanda di Gunung Kunci dibangun secara kokoh. Selain digunakan untuk hunian para prajurit dan perwira juga dijadikan tempat pertahanan. Lokasi Gunung Kunci sangat strategis untuk memantau Sumedang dan sekitarnya. Itulah sebabnya benteng tersebut dibuat di bukit tersebut. Benteng pertahanan Belanda yang saat ini sudah rusak tersebut masih terdapat adanya ruangan-ruangan, tempat meriam, lubanglubang pengintai, tangga, dan loronglorong penghubung.

Benteng Gunung Kunci dilengkapi dengan dua buah tempat meriam. Satu diarahkan langsung ke Keraton Sumedang. Langkah ini dilakukan untuk menjaga kemungkinan seandainya rakyat Sumedang melakukan perlawanan, Belanda sudah siaga untuk melakukan penghadangan. Meriam kedua diarahkan ke Bendungan Ragadiem, untuk mengantisipasi musuh datang dari luar Sumedang, masuk lewat laut utara.

Di atap benteng Gunung Kunci juga dilengkapi lubang-lubang pengintai berbentuk segi empat, yang digunakan untuk mengintai Kota Sumedang, seandainya ada musuh yang melintas atau mendekat ke benteng tersebut. Jalan darat terdekat menuju benteng adalah jalan Cadas Pangeran yang menghubungkan Kota Bandung dan Cirebon. Benteng pertahanan Gunung Kunci dilengkapi dengan kamar-kamar. Kamar-kamar tersebut dibangun untuk para perwira Belanda, para prajurit, tempat amunisi, dan kamar mandi. Dengan adanya kelengkapan tersebut secara tidak langsung, benteng tersebut selain dijadikan sebagai tempat pertahanan juga dijadikan sebagai tempat hunian.

\section{b. G unung Palasari}

Benteng ini terletak di sebelah barat Benteng Gunung Kunci, atau terletak di sebelah barat alun-alun Sumedang, tepatnya di Gunung Sindang Palay Desa Pasanggrahan Kecamatan Sumedang Selatan di kaki Gunung 
Palasari. Benteng ini dibangun di atas tanah seluas 6 ha antara tahun 1913-1917. Di benteng tersebut terdapat delapan bangunan beton, masing-masing benteng dibangun secara terpisah satu sama lain dalam bentuk melingkar. Terdiri atas 27 ruangan berpintu, 25 jendela, dan 46 ventilasi, berfungsi sebagai gudang mesiu yang hanya berjarak kurang dari $1 \mathrm{~km}$ dari Tangsi Belanda (sekarang KODIM 0610 Sumedang).

\section{c. Benteng $\mathbf{G}$ unung $\mathbf{G}$ adung}

Benteng Gunung Gadung terletak di atas bukit Gadung termasuk wilayah Kampung Gunung Gadung Desa Sukajaya Kecamatan Sumedang Selatan atau di sebelah selatan Kota Sumedang. Benteng Gunung Gadung terdiri atas tiga bangunan. Antara bangunan satu dengan bangunan lainnya berdekatan yang dihubungkan oleh jalan yang cukup lebar. Bangunan benteng di sebelah utara terletak di Pasir Kolocer menghadap ke sebelah barat mengarah ke Kota Sumedang. Bangunan lainnya menghadap ke Pasir Laja dan Pasir Dermaga. Benteng-benteng tersebut difungsikan untuk benteng pertahanan dan sekaligus dijadikan tempat persembunyian.

\section{d. Bendungan Ragadiem}

Selain membangun tiga benteng pertahanan, pemerintah kolonial juga membangun Bendungan Ragadiem. Bendungan ini dibangun di areal pesawahan di dekat Sungai Cipeles. Bendungan Ragadiem dibangun untuk mengamankan benteng pertahanan yang ada di atasnya yaitu Benteng Gunung Kunci dan Benteng Palasari. Salah satu meriam yang ada di Gunung Kunci diarahkan ke bendungan ini. Sebagai bentuk antisipasi seandainya musuh datang dari luar Sumedang untuk menyerang benteng pertahanan. Meriam akan ditembakkan dari atas benteng untuk menjebol tanggul bendungan. Dengan demikian, air bendungan akan meluap membanjiri sawah, benteng pertahanan
Gunung Kunci, Gunung Palasari, dan penghuni benteng terselamatkan. Musuh yang mendekati benteng pertahanan pun terhalang oleh luapan air bendungan (wawancara dengan Ahmad Wiriatmadja, 11 Januari 2014).

\section{Ditioeng Memeh Hoedjan}

Ditioeng Memeh Hudjan merupakan tulisan Pangeran Aria Suria Atmadja berupa dongeng yang menceriterakan kedatangan Belanda di Hindia, sikap raja-raja pribumi yang ada di Nusantara terhadap rakyatnya, keinginan Pangeran Aria Suria Atmadja untuk melatih bersenjata para pemuda pribumi di Sumedang, berisi nasihat yang ditujukan kepada rakyatnya dalam menyikapi adanya pembangunan yang dilakukan oleh Belanda di Sumedang, bahkan tidak sedikit Pangeran Suria Atmadja menggambarkan kehidupan masyarakatnya pada saat itu, seperti diceritakan dalam tulisannya;

...Mangsa harita meh di sakoeliahna agama Hindoe geus kaselek koe agama Islam aya oge sababaraha golongan anoe masih keneh nyembah ka kajoe ka watoe.... (Soeria Atmadja, 1920: 21).

Yang diartikan bahwa pada waktu itu agama Hindu telah terdesak oleh Agama Islam, ada juga beberapa golongan yang masih bertuhankan kayu dan batu....

...lobana nagara atawa keradjaan pada dibawah parentah koe radjana sorangan, eta radja-radja nyarepengna djiwa katoet banda rahayatna teh estoe sakama-kama pisan. Geus meunang sababaraha toeroenan djelemadjelema oerang dieu teh estoe maloeloe djaradi abid djeung djariah bae, matak naker ngadjaoehkeun kana kamadjoean nagara.... 
Artinya:

...Banyak negara atau kerajaan di bawah perintah raja-rajanya sendiri. Raja mengurus rakyatnya semaunya, sudah beberapa turunan orang sini hanya menjadi pesuruh, jauh dari ingin memajukan Negara....(Soeria Atmadja, 1920: 21).

Dalam menyikapi masuknya Belanda ke Hindia diceritakan dalam tulisan tersebut bahwa Belanda datang ke Hindia bertujuan untuk dagang, oleh raja-raja pribumi Belanda ditakuti dan tidak disukai.

...Taya deui kahayangna ngan dapon bisa djongdjon dagang sarta tumaninah ngoekoed oentoeng anoe sakitoe gedena bae; tapi doemeh maranehanana tambah-tambah santosa djeung boga adat hawek, koe radja-radja pribumi teh dipikasieun, tapi dipikaidjid naker.... (Soeria Atmadja, 1920: 21).

Artinya:

...tidak ada yang diinginkannya hanya berdagang, untuk mencari keuntungan sebesar-besarnya, mereka menjadi kaya tapi picik, oleh raja-raja pribumi ditakuti dan dibenci........

Bahkan buku tersebut diberi pengantar dengan dongeng (cerita) burung. Dalam dongeng tersebut Belanda diibaratkan burung pendatang yang ingin menjajah dunia, negara diibaratkan leuweung (hutan belantara), sedangkan penduduknya diibaratkan burung pribumi atau burung hutan, ada kemungkinan dongeng (cerita) tersebut untuk memperkaya bahasa dalam mengutarakan isi hatinya atau supaya mudah dimengerti oleh rakyatnya.

... Aya hidji manoek, hiber rek ngadjadjah doenya, hajangeun loba pamanggih, djeung hajangeun ngasaan kadaharan anoe araneh anoe euweuh di lemboerna.

...demi manoek semah tea, sadjeroning loemampah nyiar boeboeahan anoe araneh teh, asoepna ka djero eta leuweung beuki lila beuki nengah bae serta bari ngaweswes ngahakanan boeboeahan sakoer anoe kapanggih.

...radja-radja manoek eusi eta leuweung, anoe sakitoe lobana teh, laun-laun mah ngarasa teter teu barisaeun nyingsieunan ka eta manoek semah... ari estoe-estoena eta manoek leuweung teh barodo remen diaradoe djeung pada batoer lantaran tjetjek botjek atawa alatan mareboetkeun boeah sasiki bae geur pasea

...lawas-lawas manehanana nepi ka djlegna pisan ngaraton di dinya (Soeria Atmadja, 1920: 8).

Artinya:

...Ada satu burung ingin menjajah dunia untuk mencari pengalaman dan makanan yang aneh yang tidak ada di daerahnya. Selain mencari makanan, burung tamu tersebut masuk hutannya makin lama makin ke dalam, lama-kelamaan raja burung yang ada di hutan tersebut jadi kalah oleh burung tamu tersebut....

...pada kenyataannya burung hutan tersebut pada bodoh, senang berantem dengan teman-temannya, karena rebutan makanan...lama kelamaan burung tamu tersebut menjadi raja.

Bagaimana sikap Pangeran Aria Suria Atmadja terhadap pemerintahan kolonial Belanda? Sepertinya Pangeran Aria Suria Atmadja memilih dipimpin oleh pemerintah kolonial Belanda daripada oleh raja pribumi atau bangsa asing lainnya, hanya tidak dijelaskan dalam tulisannya tersebut apakah bangsa asing lainnya tersebut oleh Inggris atau Portugis. Seperti dalam tulisannya;

... manoek semah teh ngaratoean di sakoeliahna eta leuweung gonggong: ari boektina, nya eta bangsa Walanda ngaratoean di sakoeliahna kapoeloan Hindia. Sababaraha lawasna eta 
bangsa ngahaben bae peperangan sarta loba naker kagorenganana sadjeroning ngaheujeuk nagara jeung tjari oentoeng teh, teu pisan ngoeroes ka djalma-djalma anoe djaradi bawahanana....

...Heuteu ari goreng-goreng teuing onaman, malah tinimbang di bawah parentah radja-radjana pribadi mah, eta somahan-somahan teh kawasna nya mending keneh di bawah parentah Walanda, nadjan sedjensedjen bangsa asing oge, moen mangsa harita njarekel kapoeloan Hindia moal leuwih ti kitoe hemanna ka somahan. .......

Artinya:

...Burung tamu telah menjadi raja di hutan tersebut yaitu bangsa Belanda menjadi raja di Kepulauan Hindia, sudah beberapa lamanya bangsa tersebut terus saja berperang serta banyak sekali kejelekannya. Selain mencari untung juga tidak mengurus orang-orang bawahannya (rakyatnya pen)....

...Jelek sekali sih tidak, malah daripada dipimpin oleh raja-rajanya sendiri lebih baik di bawah perintah Belanda, bangsa asing yang lain juga apabila menguasai Kepulauan Hindia pasti akan berbuat seperti itu kepada rakyatnya....

Dalam hal permintaan Pangeran Aria untuk melatih senjata para pemuda pilihan kepada Belanda, dalam buku "Ditioeng Memeh Hoedjan" Pangeran Aria Suria Atmadja merujuk pada cerita (dongeng) burung pribumi yang meminta dilatih berperang kepada rajanya (burung pendatang). Terlepas dari apakah dongeng yang dimaksud tersebut merupakan cerita fiksi atau nonfiksi, yang jelas tetap cerita tersebut perlu diapresiasi sebagai karya luhung yang berisikan keinginan, cita-cita dan harapan Pangeran Aria Suria Atmadja untuk melatih para pemuda pinilih Sumedang untuk dilatih belajar bersenjata. Pangeran Aria pun mengupas dalam tulisannya tentang keuntungannya belajar berlatih senjata atau ikut lakon djoerit dalam tulisannya Ditioeng Memeh Hoedjan halaman 36. Lakon Djoerit bukan saja supaya tangkas menggunakan senjata untuk melawan musuh, akan tetapi juga untuk menambah harkat dan martabat orang pribumi, karena dalam berlatih kemiliteran, dilatih juga untuk menuruti perundang-undangan dan perintah, menjaga ketertiban baik di rumah maupun di tempat kerja, memelihara barang-barang pribadi atau pun barang titipan, serta belajar gotong-royong dalam mengerjakan sesuatu.

Dalam meminta pemuda pilihan untuk dididik berlatih senjata kepada Belanda digambarkan dalam cerita (Dongeng) Burung berikut.

\section{DONGENG}

...Noen, Gusti! abdi sadaya ngaraos rempan sareng hariwang pisan, reh ninggal pibalahieun, nja eta aja manoek ageung, moereleng bae ngileng-ngileng leuweung oerang ... (Soeria Atmadja, 1920: 10).

...Moegi ajeuna koe pitandang Dampal Goesti kadigdjajaanana abdiabdi sina sami sareng kapinteranana; moegi abdi-abdi woeroekan, koemaha pitarekaheunana guesan ngabasmi moesoeh. Bo, Goesti! Abdi-abdi teh ajeuna hengker keneh, moeng Gusti noe piiasaeun nambahan kakiatan, nja eta soepados abdi-abdi sadaja mangke dina proengna taroeng waktoena dongkap bahla tea, tiasa bela pati ka Dampal Goesti. Patekadan abdi-abdi sadaya taja sanes, moeng hajang tiasa lambat lamboet koemawoela ka Dampal Goesti, dalah dina papaitna oge hajang sasarengan nja eta ngabelaan ieu leuweung lemah tjai abdi sadaya (Soeria Atmadja, 1920: 11). 
Artinya:

\section{CERITA}

...Noen, Gusti! ${ }^{7}$ Saya semuanya merasa was-was melihat bahaya yaitu ada burung besar (musuh pen.) sedang mengawasi tempat kita.

.....Saya mohon dengan kekuasaan dan kekuatan, saya semuanya meminta diberi pelajaran bagaimana caranya untuk mengusir musuh, saya semuanya sekarang belum bisa, hanya "Gusti" yang bisa memberi kekuatan yaitu supaya kita semuanya sewaktu datang bahaya, bisa membela "Dampal Gusti". Tekad saya semuanya sedikit demi sedikit bisa membela "Dampal Gusti", malah dalam keadaan pahit pun mau samasama membela hutan tempat kelahiran....

........waktoe njanggakeun pioenjoek geusan ngajakeun kamistian lakon djoeorit tea, loba djalma-djalma anoe teu moepakateun, sarta ngelingan, pokna: oelah mere peso ka boedak, bisi matak raheut..... (Soeria Atmadja, 1920: 34).

Artinya:

...waktu menyampaikan permohonan "lakon djoerit" tersebut banyak orangorang yang tidak setuju, serta memberi nasihat katanya; jangan memberi pisau kepada anak kecil, nanti bisa luka......

Setelah menunggu jawaban beberapa waktu lamanya, permintaan pelatihan menggunakan senjata pun akhirnya mendapat jawaban.

......Noehoen, he oetoesan-oetoesan, anoe djaradi wakil rahayat kami!. Pioenjoek maraneh kabeh bener, nepi ka hate kami ajeuna ngarasa longsong

7 Panggilan kehormatan seorang abdi raja kepada rajanya yang diagung-agungkan dan dihormati. djeung oeroet kami bingoeng karasana ajeuna djadi boengangang. Tadina dina wiwaha kami, teu hade mere peso ka boedak, bisi matak raheut, boh ka manehanana pribadi, boh ka anoe sedjen. Tapi tetela ari anoe omonganana tjara maraneh mah lain boedak. Ajeuna tina sabab maraneh pertjaja ka kami, kami oge pertjaja ka maraneh. heug atoeh, arek mere pakarang ka maraneh, sarta arek mapatahan koemaha metakeunana eta pakarang pikeun ngalawan moesoeh anoe arasoep $k a$ dieu. Dalah anoe halengker age tangtoe diiker-iker saboedi akal, dipake ngelaksanakeun ieu maksoed anoe sakieu gedena.

Mangke dimana datang sikoe si woeloe-woeloe galagah kantjana, oerang geus sajaga. Maraneh koedoe ngiring ka kami, kami anoe ti heula, sabab kanyaah kami kana ieu leuweung teh saroea bae djeung $\mathrm{ka}$ maraneh (Soeria Atmadja, 1920; 12)

Artinya:

.....Terima kasih, he para utusan, yang telah menjadi wakil rakyat kami! Permohonan kalian semua benar, sehingga hati kami menjadi tenang, tadinya kami merasa tidak setuju, merasa tidak baik memberi pisau kepada anak kecil, khawatir takut terluka. Sekarang karena kalian percaya kepada kami, kami juga percaya kepada kalian, sekarang kami akan memberi persenjataan kepada kalian, dan akan memberi pelatihan bagaimana cara menggunakannya untuk melawan musuh yang masuk ke wilayah kita.

Nanti apabila datang "sikoe siwoeloe-woeloe galagah kancana" kita sudah siaga. Kalian harus ikut kami, kami yang lebih dahulu sebab rasa sayang kami pada tempat ini sama saja dengan merasa sayang pada kalian 
Tina pana'na kana dialadjar peperangan tangtoe bae loba anoe kasamboet koe pada batoer; tapi sakoer anoe kasamboet teh geuwat dioeroes dibeber tatoena koe manoek-manoek anoe halengkeur, anoe teu karoeateun diadjar peperangan Katjida saroehoedna djeung saragepna teh.

Radja manoek boengah; bener ari heuteu sakabeh tea mah rahajatna soehoed kana diadjar peperangan, malah sok aja anoe maling-maling njalingker ngadon naon bae api-api, atawa tampolana mah ngan ngadon tjitjing bae; manehanana ngama'loem tina nyahoeun tea. Jen eta mah manoek-manoek noe karitoe peta teh. Masih barodo keneh taja pigoenaeunana nadjan kapareng kataradjang bantjang-pakewoeh oge (Soeria Atmadja, 1920; 13)

Artinya:......

Disebabkan oleh seriusnya belajar berperang, tentu saja banyak yang terluka oleh temannya sendiri, akan tetapi yang terluka dengan cepat dirawat lukanya oleh burung-burung yang kuat. Raja burung merasa senang hati. Memang benar tidak semua rakyatnya serius belajar, malah suka ada yang mencuri, nyelinap, ngumpet, pura-pura atau malah diam, ia dimaklumi bahwa burung-burung seperti itu malah bodoh tidak ada gunanya meskipun terjadi yang tidak diharapkan.

Sabot eta manoek-manoek keur karitoe, manoek gede anoe aja dina leuweung leutik, noe teu eureuneureun moereleng ngawas-ngawas kana eta leuweung ganggong tea. Ngadenge anoe ear-earan, nja eta sora manoek leuweung anoe keur dialadjar peperangan tea.

Mimitina mah dina sangka eta manoek gede teh maroekan manoekmanoek eusi leuweung tea keur pasea rosa djeung pada batoerna. Tapi teu koengsi lila koe manehna katendjo radja manoek teu keur hiber kakalajangan ngapalaan manoekmanoek anoe geus tarabah kana peta-peta peperangan (Soeria Atmadja, 1920; 13)

Artinya: ....

Sewaktu burung-burung sedang belajar berperang, burung besar yang berada di hutan kecil yang sedang mengincar dan mengawasi hutan tempat belajar tersebut, mendengar suara ramai oleh burung yang sedang belajar berperang tersebut. Awalnya mengira burung-burung tersebut sedang bertengkar, akan tetapi terlihat rajanya sedang terbang mengepalai burung-burung yang sudah mengerti cara-cara berperang.

.......Katjaritakeun eta manoekmanoek leuweung teh beuki tambah pinter jeung beuki tambah koeat bae lantaran dipakihikeun koe radjana, tambah-tambah silih pertjaja jeung silih pikanyaah. Laoen-laoen manoek-manoek leuweung teh pinterna sarua bae jeung radjana..(Soeria Atmadja, 1920:14)

Artinya:

Diceritakan burung-burung hutan tersebut makin bertambah pintar dan semakin tambah kuat disebabkan "dipakihikeun" oleh rajanya ditambah dikarenakan saling percaya dan saling menyayangi. Lamakelamaan burung-burung hutan tersebut kepintarannya sama dengan rajanya.

Adanya pembangunan benteng pun disinggung dalam buku tersebut:

........Oerang Walanda, karepna di Hindia teh arek njieun wawangoenan anoe aloes toer koeat. Pademen-pademenna 
Anggeus dipasang, kari tembokna. Keun sina apik masangmasangkeunana bata soepaja eta wawangoenan oelah tereh roentoeh, djeung oerang pada miloe ngadoedoea moega-moega oelah hoedjan, soepaja oelah aja waktoe anoe kapitjeun, oelah moebah gawena. Sadaya anoe maraos ieu boekoe, dalah koering oge manawi moal kantos ngalaman kana parantosna pisan mah eta wawangoenan teh, sanadjan dipidamelna digeretek oge ajeuna dina waktoe-waktoe ieu, parantos loehoer oge terapna tembok teh awahing koe diangsit, nanging ari kana parantosna pisan mah, tangeh keneh. Anoe kagoengan damel, koe kakara ningali sakieu oge ngaraos bingah, tina teu njana. Namoeng sakedah polah, tjing oerang pada amal noeloeng $\mathrm{ka}$ eta anoe kagoengan damel (anoe ngadegkeun) soepados takadjarna gede mangfa'atna $k a$ anak intjoe oerang lamoen kitoe rineh temen oerang madep ka Pangeran, dina tjoendoek $\mathrm{ka}$ waktoe, tepi ka titistoelis poepoet oemoer, tina moal njoreang ka toekang, da geus taja genah panasaran, pedah reugreug geus boga keur ninggalan anoe aja..... (Soeria Atmadja, 1920: 41)

Artinya:

.........orang Belanda di Hindia mempunyai maksud untuk mendirikan bangunan yang bagus dan kuat. Segalanya sudah disiapkan, tinggal temboknya. Biarkan supaya memasangnya rapih bangunannya kuat. Kita sama-sama ikut berdoa semoga tidak turun hujan, supaya tidak ada waktu yang terbuang, pekerjaannya tidak mubah. Semua yang membaca buku ini malah saya sendiri sepertinya tidak akan mengalami sampai rampungnya pembangunan tersebut pada waktu- waktu sekarang, meskipun pekerjaannya akan dipercepat. Termasuk sudah tinggi juga pemasangan tembok tersebut, karena pengerjaannya dipercepat, akan tetapi sampai selesainya bangunan tersebut masih jauh. Dengan melihat pekerjaan baru selesai segini juga, yang mempunyai pekerjaan sudah merasa senang karena tidak terduga. Akan tetapi cobalah kita bersamasama menolong kepada yang mempunyai pekerjaan (yang membangun) supaya nantinya besar manfaatnya untuk anak cucu kita. Kalau sudah begitu pasti tenang menghadap kepada Yang Kuasa nanti, kalau sudah sampai pada titis tulis "puput umur" tidak penasaran karena sudah tenang meninggalkan sesuatu untuk yang masih hidup......

Itulah pemikiran-pemikiran Pangeran Aria Suria Atmadja yang dituangkan dalam sebuah buku "Ditioeng Memeh Hoedjan". Seolah-olah memberitahukan kepada rakyatnya, biarlah Belanda membuat bangunan-bangunan yang banyak dan kokoh nantinya bakal menjadi milik kita.

Pangeran Aria Suria Atmadja diangkat menjadi bupati berdasarkan pada garis keturunan. Biasanya setiap bupati yang lengser dari jabatannya akan mewariskan barang pusakanya kepada penggantinya. Barang pusaka yang diwariskan dapat berupa tanah, sawah, kebun, dan barang pusaka berharga lainnya seperti keris tombak, dan sebagainya. Tujuan mewariskan barang pusaka tersebut untuk bekal hidup selama menjabat sebagai bupati. Begitu pula dengan Pangeran Aria Suria Atmadja. Ia mendapatkan warisan pusaka peninggalan dari ayahnya Pangeran Aria Suria Adinata yang dikenal dengan nama Pangeran Sugih. Pada 22 September 1912, Pangeran Aria Suria Atmadja mewakafkan pusakapusaka miliknya yang ia namakan sebagai "banda kaoela pitoein", "poesaka ti 
sepoeh", dan "asal poesaka ti sepoehsepoeh" kepada adiknya seayah karena ia tidak mempunyai anak laki-laki. Ia membuat wasiat yang berisi barang-barang pusaka tersebut akan diwakafkan kepada adiknya Tumenggung Kusumadilaga. Barang yang diwakafkan tidak boleh diwariskan, tidak boleh digugat oleh siapa pun, tidak boleh dijual, tidak boleh diubahubah, tidak boleh ditukar dan diganti. Dengan demikian keutuhan, kebulatan dan kelengkapan barang pusaka terjamin. Wakaf mulai berlaku jika Pangeran Aria Suria Atmadja berhenti sebagai bupati Sumedang atau wafat (Surianingrat, 1983: 145). Pada 1919 Pangeran Aria Suria Atmadja berhenti sebagai bupati Sumedang dengan mendapat pensiun. Pada 30 Mei 1919 dilakukan penyerahan barang "Asal Poesaka ti Sepoeh-sepoeh" dan "Tina Oesaha Kaoela Pribadi" kepada Tumenggung Kusumadilaga.

Pangeran Aria Suria Atmadja yang selama menjabat sebagai bupati, telah banyak berjasa kepada rakyatnya. Ia pun mendapat penghargaan atau tanda jasa dari pemerintah kolonial Belanda. Di antara salah satu tanda jasanya Groot Gouden Ster (1891) dan dianugerahi beberapa bintang jasa tahun 1901, 1903, 1918, Payung Song-song Kuning tahun 1905, Gelar Adipati 1898, Gelar Aria 1906 dan Gelar Pangeran 1910.

Pada 1921, Pangeran Aria Suria Atmadja beserta isteri menunaikan ibadah haji. Di tengah menunaikan ibadah haji tersebut ia wafat di Mekah pada 1 Juni 1921, dan dimakamkan di daerah Ma'la, Mekah Al-Mukaromah. Ia kemudian dikenal dengan nama Pangeran Mekah. Untuk menghormati jasa-jasanya, pada 25 April 1922 didirikan sebuah monumen berbentuk Lingga di tengah alun-alun Sumedang. Monumen tersebut diresmikan oleh Gubernur Jenderal D. Fock serta dihadiri para bupati, residen se-Priangan, serta pejabat-pejabat Belanda dan pribumi.

Prasasti tersebut bertuliskan dalam bahasa Belanda " dit monument werd ngewijd op Dinslag 25 April 1922”, dan tulisan dalam bahasa Sunda, yaitu Pangabakti ka suwargina Kangjeng Pangeran Aria Soeria Atmadja, bupati Sumedang, 1882 - 1919, dilahirkeun di Sumedang ping 11-1-1851, wafat di Mekah ping 1 Juni 1921. Setelah Pangeran Suriatmadja wafat, ia digantikan oleh Adipati Kusumahdilaga (Hardjasaputra, 2005: 59).

\section{PENUTUP}

Pangeran Aria Suria Atmadja adalah satu di antara para bupati Sumedang yang memajukan Sumedang dalam segala bidang. Ia seorang yang cerdik dan pandai, serta mampu meningkatkan kesejahteraan rakyatnya di berbagai sektor. Dengan sikap kesahajaannya ia berhasil membuat Belanda was-was. Dengan keinginannya supaya pemuda Sumedang dapat dilatih militer, Belanda tidak mengizinkan bahkan menjawabnya dengan membangun benteng pertahanan. Benteng Pertahanan Gunung Kunci dibangun dengan dilengkapi meriam yang diarahkan ke Keraton Sumedang. Hal tersebut mengingatkan kepada benteng VOC di Jayakarta yang juga dibangun dan diarahkan ke keraton. Dengan dibangunnya benteng pertahanan militer di Sumedang tersebut pada dasarnya Belanda merasa ketakutan akan adanya pemberontakan. Setelah Pangeran Suria Atmadja meminta para pemuda pribumi untuk dilatih militer, Belanda pun menolak keinginan Pangeran Suria Atmadja, karena tidak menginginkan daerah jajahannya pintar memainkan senjata, yang akan merugikan dirinya bahkan mengakibatkan senjata makan tuan.

Di masa kekuasaannya, Pangeran Aria Suria Amadja telah memikirkan kemerdekaan jauh ke depan. Jiwa nasionalismenya tinggi. Ia ingin melepaskan diri dari belenggu pemerintah kolonial. Akan tetapi ia pun memikirkan keselamatan rakyatnya yang masih buta dalam hal persenjataan. 
Tiga benteng pertahanan militer dan bendungan yang telah dibangun pemerintah kolonial tersebut akhirnya hanya dijadikan monumen semata yang selama kepemimpinan Aria Suria Atmadja tidak pernah melakukan perlawanan.

Di satu sisi ada kemungkinan bahwa dibangunnya benteng tersebut diperuntukkan sebagai tempat pertahanan perwira Belanda yang akan menjadikan Sumedang sebagai penyangga ibu kota Hindia Belanda yang rencananya akan dipindahkan ke Bandung. Kenyataannya rencana pembangunan pusat pemerintahan Hindia Belanda di Bandung tak kunjung kesampaian.

Dengan kearifan hatinya, Pangeran Aria Suria Atmadja sangat memerhatikan nasib rakyatnya. Rakyat Sumedang pun sangat menghormatinya, sehingga kiprah Pangeran Aria Suria Atmadja pun sangat diperhitungkan oleh pemerintah kolonial. Barangkali pemerintah kolonial belajar dari pengalaman terdahulu ketika bupati Sumedang dijabat oleh Pangeran Kornel yang begitu memerhatikan nasib rakyatnya. Pangeran Kornel berani menentang Gubernur Jenderal Daendels ketika sedang mengontrol pengerjaan jalan Cadas Pangeran Sumedang.

\section{UCAPAN TERIMA KASIH}

Penulis mengucapkan terima kasih kepada Ketua Yayasan Pangeran Sumedang dan Ketua Rumah Baca Buku Sunda yang telah meminjamkan buku Ditioeng Memeh Hoedjan, dan semua pihak yang telah memberikan bantuan pada saat penelitian tersebut.

\section{DAFTAR SU MBER}

\section{Buku}

Hardjasaputera, Sobana. 2004.

"Bupati di Priangan dan Peranannya pada Abad ke-17- abad ke-19" dalam Bupati Priangan dan Kajian Lainnya mengenai Budaya Sunda. Bandung: Pusat Studi Sunda.
2005.

Sejarah Sumedang untuk Sekolah Lanjutan. Bandung: Kerjasama Dinas Kebudayaan dan Pariwisata Kabupaten Sumedang dengan Yayasan Pusat Studi Sunda dan Jurusan Sejarah Fakultas Sastra Universitas Padjadjaran.

Jubaedah, Edah. 2005.

Titilar Karuhun, Perubahan Budaya di Sumedang Abad XVI-XVII. Bandung: Paragraf.

Kunto, Haryoto. 1986. Semerbak Bunga di Bandung Raya. Bandung: Granesia.

Kuntowijoyo. 2003. Metodologi Sejarah, edisi kedua. Yogyakarta: Tiara Wacana.

Lubis, Nina Herlina. 2000.

"Sumedang", dalam Sejarah KotaKota Lama di Jawa Barat. Bandung: Alqaprint.

2008.

Sejarah Sumedang dari Masa ke Masa. Sumedang: Dinas Pariwisata dan Kebudayaan Kabupaten Sumedang.

Pusat Bahasa Departemen Pendidikan Nasinal. 2011.

Kamus Besar Bahasa Indonesia, edisi keempat. Jakarta: Gramedia.

Soeria Atmadja, Aria. 1920. Ditioeng Memeh Hoedjan. Tidak diterbitkan.

Suryadi, Didi. 1972.

Sedjarah Sumedang. Bandung: Jurusan Sejarah Fakultas Sastra Universitas Padjadjaran.

Subarkah, Imam. 1994. Sekilas 125 Tahun Kereta Api Kita (1967-1992). Tidak diterbitkan.

Suryaman, Nanang, Yeni Mulyani Sunarya, Abdul Syukur. 996. Mengenal Museum Prabu Geusan Ulun serta Riwayat Leluhur Sumedang. Tidak diterbitkan 
Tamburaka, Rustam E. 1999.

Pengantar Ilmu Sejarah Teori Filsafat Sejarah, Sejarah Filsafat dan Iptek. Jakarta: Rineka Cipta.

Wiriaatmadja, R. Moch Ahmad. 2002. Peninggalan Instalasi Militer Hindia Belanda Era Perang Dunia I 19141918 di Kota Sumedang. Tidak diterbitkan.

Yayasan Untuk Indonesia. 2005.

Ensiklopedi Jakarta, Culture \& Heritage, buku I. Jakarta: Pemerintah Provinsi Daerah Khusus Ibukota Jakarta Dinas Kebudayaan dan Pariwisata.

\section{Surat kabar}

Solihat, Kodar. 2005.

"Kereta Api Rancaekek-JatinangorTanjungsari Menyimpan Banyak Kenangan". Pikiran Rakyat, 5 Juli 2005, hlm. 21.

\section{Internet}

"Pangeran Suria Atmadja atau Pangeran Mekkah, Bupati Sumedang ke-20", diakses dari www.babadsunda. blogspot.com, tanggal 8 Januari 2013, jam.15.04.

Hermawan, Iwan "Bandung sebagai Ibukota Hindia Belanda", diakses dari http://geohistori.blogspot.com, tanggal 3 Januari 2014, jam. 13.45.

Muhsin. Z, Mumuh, "Pangeran Aria Suria Atmadja (11 Januari 1851-1 Juni 1921)", Makalah yang disampaikan dalam "Seminar Nasional Pengusulan Pangeran Suria Atmadja sebagai pahlawan nasional, diakses dari pustaka.unpad.ac.id, tanggal 9 Januari 2014, jam. 06.14. 